\title{
Visitando memórias, descobrindo sentidos - a escuta de egressos do programa curumim do sesc
}

\author{
Visiting memories, discovering meanings - listening to former participants \\ of the sesc curumim program
}

\author{
Silvio Luiz da Costa \\ Doutor em Educação \\ Universidade de Taubaté - UNITAU \\ Taubaté, SP - Brasil \\ silvio.lcosta@unitau.br \\ Cleusa Vieira da Costa \\ Mestre em Educação \\ Universidade de Taubaté - UNITAU \\ Taubaté, SP - Brasil \\ cleusavieiradacosta@gmail.com \\ Tayná Meireles de Morais \\ Graduada em Pedagogia \\ Universidade de Taubaté - UNITAU \\ Taubaté, SP - Brasil \\ meirelestayna11@gmail.com
}

\begin{abstract}
Resumo: Este artigo é decorrente de uma pesquisa mais ampla sobre a educação não formal e objetiva refletir sobre as implicações e as contribuições da participação em outros espaços de educação na vida dos sujeitos, inclusive em sua trajetória escolar. A pesquisa foi realizada com egressos do Programa Curumim do Sesc e constituiu-se de uma abordagem qualitativa, de natureza exploratória, assentada teoricamente nos estudos de Gadotti (2005), Gohn (2006) e Bourdieu (2003a, 2003b). As falas dos egressos foram analisadas com base na análise de conteúdos proposta por Bardin (2011), organizando-se em categorias os temas recorrentes, o que permitiu identificar a significância da participação dos sujeitos em espaços de educação não formal e suas repercussões na valorização da vida escolar, na preparação para os desafios e decisões da vida adulta e na inserção na comunidade.
\end{abstract}

Palavras chave: educação não formal; programa curumim; formação do sujeito; memórias.

Abstract: This article is the result of a broader research on non-formal education and it aims to reflect on the implications and contributions of participation in other educational spaces in the lives of subjects, including their school trajectory. The research was carried out with former participants of the Sesc Curumim Program and it consisted of a qualitative approach, of an exploratory nature, theoretically based on studies by Gadotti (2005), Gohn (2006) and Bourdieu (2003a, 2003b). The speeches of the former participants were analyzed based on the content analysis proposed by Bardin (2011), organizing the recurrent themes into categories, which allowed us to identify the significance of the subjects' participation in non-formal education spaces and its repercussions on valuing school life, preparation for the challenges and decisions of adulthood and inclusion in the community.

Key-words: non-formal education; curumim program; subject formation; memories.

Cite como

(ABNT NBR 6023:2018)

COSTA, Silvio Luiz; COSTA, Cleusa Vieira; MORAIS, Tayná Meireles. Visitando memórias, descobrindo sentidos - a escuta de egressos do programa curumim do sesc. Dialogia, São Paulo, n. 39, p. 1-17, e20626, set./dez. 2021. Disponível em: https://doi.org/10.5585/39.2021.20626.

American Psychological Association (APA)

Costa, S. L., Costa, C. V., \& Morais, T. M. (2021, set./dez.) Visitando memórias, descobrindo sentidos - a escuta de egressos do programa curumim do sesc. Dialogia, São Paulo, 39, p. 1-17, e20626. https://doi.org/10.5585/39.2021.20626. 


\section{A educação em todo lugar}

A educação acontece em diferentes tempos e espaços a partir das muitas relações estabelecidas com o meio e com os outros. Encontramo-nos em constante processo educativo, somos educados e reeducados a todo momento. Como afirma Brandão (1986, p. 7), "ninguém escapa da educação", o que nos leva a refletir que não há uma única forma de educar, tornando mais apropriado o uso do termo "educações". A educação espelha os valores de uma sociedade e ajuda a pensar tipos de homens. Mais do que isso, "ela ajuda a criá-los, através de passar de uns para os outros o saber que os constitui e legitima” (BRANDÃO, 1986, p. 11). Todo grupo busca formar pessoas, e cada um deles é motivado por perspectivas próprias do contexto em que está inserido, projetando modos de ser e agir e de reconhecimento de si e do outro.

Ao considerarmos a educação em sua pluralidade, ampliamos a percepção sobre seu papel na sociedade. Os significados atribuídos à educação são nutridos pelo modo de vida e valores de cada povo; assim, a educação pode atender diferentemente às necessidades de cada grupo. Constantemente, ao redor do mundo, a educação foi - e ainda é - compreendida como meio para superação de conflitos e dificuldades. Há sempre algo para ser feito, ou um “que fazer".

Para Freire (2013), essa consciência do inacabamento traz a possibilidade de ir além dele, com a consciência do indivíduo sobre si mesmo e a sua condição. Ou seja, considerando que somos seres inacabados e condicionados, e que estamos em permanente processo de desenvolvimento, atribui-se à educação o ofício da construção da humanidade. Inacabados, pois estamos em constante construção e reconstrução de valores, aprendizados, atitudes. Condicionados, porque há uma educação que carrega tanto este potencial de inovação e transformação como também de reprodução ou acomodação social.

Desse modo, compreendemos que a educação não é neutra, uma vez que corresponde às expectativas de um modelo de ser e viver. Mas também não é imutável, visto que é um processo que possibilita transformações na sociedade, consistindo numa busca contínua pela formação humana.

Nesse contexto, está posta a questão do direito social à educação, que é "sempre proclamado como prioridade, mas nem sempre cumprido e garantido na prática" (GADOTTI, 2005, p. 1). Esse direito social parte de uma visão que compreende a totalidade de uma sociedade democrática, ultrapassando a concepção individualista e concebendo que determinados direitos são inerentes a todos, e não a determinados indivíduos ou grupos, compreensão essa que reconhece a relevância da educação para uma sociedade mais justa. 
O reconhecimento da educação como um direito aponta para o que ela pode significar na vida das pessoas, tendo em vista que inclui e exclui. Quando esse direito é negado, prejudica-se o exercício pleno da cidadania. Ou seja, ao negar o direito à educação, dificulta-se também o acesso a outros direitos, não reconhecendo o indivíduo enquanto cidadão. Sendo assim, salienta-se a necessidade de valorização do direito à educação para a conscientização e a garantia de outros direitos.

Trata-se de um direito que por vezes foi associado meramente ao ensino obrigatório e gratuito, o que reconhecemos como "Educação Básica". Essa concepção convida-nos a retomar Brandão (1986, p. 16), quando este afirma que "a educação existe sob tantas formas e é praticada em situações tão diferentes, que algumas vezes parece ser invisível, a não ser nos lugares onde pendura alguma placa na porta com o seu nome". Nessa direção, cabe ressaltar que a realização do direito à educação não é uma prerrogativa apenas da escola, pois a educação acontece em diferentes cenários. Aprendemos nos mais diferentes ambientes. Aliás, Gadotti (2005, p. 1) sumariza que o “direito à educação é, sobretudo, o direito de aprender". Conscientes disso, podemos acrescentar que não apenas passamos pelos espaços, mas aprendemos com eles e neles.

Considerando o potencial educativo dos espaços e admitindo as diferentes modalidades de educação, os esforços deste texto consistem, inicialmente, no reconhecimento da educação não formal e sua relevância no processo formativo dos sujeitos. Nesse sentido, este estudo focalizou egressos do Programa Curumim do Serviço Social do Comércio (Sesc), com a pretensão de revisitar suas memórias e, por meio delas, investigar o papel desempenhado por esse espaço de educação no processo formativo de seus participantes. Assim, pretende-se, partindo-se da voz daqueles que passaram pelo Programa Curumim, refletir sobre a significância da participação em espaços de educação não escolares e suas contribuições para a vida dos sujeitos, inclusive em sua trajetória escolar.

\section{Descortinando educações}

Compreender a educação em sua abrangência supõe o reconhecimento de suas diferentes modalidades: a educação não formal, a educação informal e a educação formal. Apesar das distinções que se possa estabelecer, não há um modo único de elas acontecerem e todas repercutem na formação dos sujeitos.

A modalidade certamente mais reconhecida é a educação formal, a que se refere à educação escolar. No Brasil a legislação determina que crianças e adolescentes passem aproximadamente 14 anos dentro da escola, o que torna a instituição referência para os cidadãos. Essa modalidade formal 
tem por objetivo, segundo Gohn (2006), o ensino-aprendizagem de saberes e conteúdos previamente demarcados e historicamente sistematizados. Nas palavras da pesquisadora:

\begin{abstract}
A educação formal requer tempo, local específico, pessoal especializado, organização de vários tipos (inclusive a curricular), sistematização sequencial das atividades, disciplinamento, regulamentos e leis, órgãos superiores etc. Ela tem caráter metódico e, usualmente, divide-se por idade/classe de conhecimento. (GOHN, 2006, p. 30).
\end{abstract}

Essa concepção demonstra características que estão presentes na educação formal, porém, não são exclusivas da modalidade. A escola é a principal instituição em que ocorre a educação formal, entretanto, a formação do indivíduo conta com a influência de outros espaços ou instituições. "Todas as situações entre pessoas, e entre pessoas e a natureza - situações sempre mediadas pelas regras, símbolos e valores da cultura do grupo - têm, em menor ou maior escala a sua dimensão pedagógica" (BRANDÃO, 1986, p. 20). Nessa perspectiva, reconhecemos as características que definem a educação formal, mas realçamos sua presença em outras instituições, além da escolar, uma vez que "toda educação é, de certa forma, educação formal, no sentido de ser intencional, mas o cenário pode ser diferente" (GADOT'TI, 2005, p. 2).

Já a educação informal é a primeira forma de educação com que entramos em contato, sendo frequentemente associada à família. É aquela que acontece no cotidiano, caracterizada pelas individualidades de cada grupo e por suas crenças, valores, concepções, hábitos. Ela ocorre espontaneamente no decorrer da vida, entre familiares, amigos, manifestações religiosas, culturais, visitas a museus, teatros, leituras de livros, entre outros. Nessa modalidade todos podem ser responsáveis pelo processo de ensino-aprendizagem, o que pode acontecer intencionalmente ou não.

A educação informal tem seus espaços educativos demarcados por referências de nacionalidade, localidade, idade, sexo, religião, etnia etc. A casa onde se mora, a rua, o bairro, o condomínio, o clube que se frequente, a igreja ou o local de culto a que se vincula sua crença religiosa, o local onde se nasceu etc. (GOHN, 2006, p. 29).

A educação informal ocorre durante o processo de socialização, no qual os indivíduos relacionam-se com o ensino-aprendizado conduzido por seus "valores e culturas próprias, de pertencimento e sentimentos herdados" (GOHN, 2006, p. 28). Isso demonstra que, comumente, o processo de ensino-aprendizagem dos indivíduos estará vinculado e delimitado ao universo de seus pares, com as relações pautadas a partir de seus gostos, preferências, hábitos e, até mesmo, pertencimentos herdados.

Por fim, quando falamos em educação não formal, deparamo-nos com divergências terminológicas. Isso porque há autores que a reconhecem como parte da educação informal e 
outros que descortinam as especificidades de cada uma dessas modalidades. Segundo Marandino (2017), autores de língua inglesa empregam termos voltados para a compreensão de educação informal e não formal como uma única modalidade, enquanto autores de língua portuguesa, grande parte das vezes, dividem essas modalidades.

Ainda de acordo com a pesquisadora, em países latino-americanos, é comum a divisão da educação em formal, não formal e informal, o que se deve aos contextos que afetaram a educação a partir da década de 60 , onde se passou a procurar uma formação política do indivíduo - um processo que ocorria nas organizações e espaços das comunidades, tais como igrejas, sindicatos e associações de moradores. Nesse contexto, no Brasil a educação não formal, quando tinha visibilidade, era ainda associada a programas e campanhas de educação de jovens e adultos. Contudo, esse cenário começa a se alterar nos anos 90, com as mudanças na economia, na sociedade e no mundo do trabalho.

A educação não formal é "aquela que se aprende 'no mundo da vida', via os processos de compartilhamento de experiências, principalmente em espaços e ações coletivos cotidianas" (GOHN, 2006, p. 28). Essa modalidade transcorre a partir de situações reais e interativas, que são marcadas pela intencionalidade de trocas de saberes e experiências decorrentes de necessidades e interesses de cada grupo; assim, suas diretrizes são moldadas pela coletividade. Nos espaços de educação não formal, procura-se oferecer formação política e sociocultural, reconhecendo a indispensabilidade da formação integral dos indivíduos.

Ao destacar as características das modalidades da educação, não buscamos a segmentação delas, e sim a complementação. Essas delimitações devem ser consideradas como características meramente didáticas, para uma melhor compreensão de cada modalidade. Porém, para se reconhecer uma modalidade, é preciso saber quem e como se está atuando nela.

Dessa forma, um museu, por exemplo, poderia ser nomeado como um espaço de
educação não formal quando o pensamos como uma instituição que possui um projeto
estruturado e com um determinado conteúdo programático e, em especial, com
intencionalidades educativas determinadas. Contudo, sob o olhar do público, poderíamos
considerá-lo, por exemplo, como educação formal, quando alunos o visitam com uma
atividade totalmente estruturada por sua escola, buscando um aprofundamento em um
determinado conteúdo específico. E podemos, ainda sob o olhar do público, imaginá-lo
como educação informal, ao pensarmos em um visitante que procura um museu para
uma experiência de fruição e entretenimento em um final-de-semana com seus amigos
ou familiares. (MARANDINO, 2017, p. 813).

O significativo é que, independentemente da forma pela qual o indivíduo realiza a sua experiência de educação em espaços não escolares, como, por exemplo, a visita a um museu, ela repercute em seu processo formativo. Essa compreensão encontra eco nas reflexões de Bourdieu (2003b). Para ele, os indivíduos são socialmente constituídos e, por isso, não podem ser 
interpretados somente por um viés das escolhas, preferências e ações individuais. Pensar assim iria reduzi-los a seres isolados, e não seres que afetam e são afetados pela sociedade.

Nessa direção, quando a criança ou o adolescente participa em outros espaços, que não o escolar, ela amplia a sua rede de relações, conhece outras pessoas e lugares, participa de outras atividades e amplia o seu repertório. Esse movimento do sujeito contribui para a "extensão da rede de relações", tendo como efeito não apenas uma ampliação do seu capital social, mas também dos modos de dispô-lo a seu favor. Ou seja, ter a posse de um dado capital e ser capaz de mobilizá-lo. Conhecer pessoas, instituições e acioná-las da melhor maneira em função de suas necessidades.

Ainda seguindo Bourdieu (2003a), os indivíduos carregam bagagens sociais e culturais diferenciadas, e estas podem tornar as condições mais ou menos favoráveis no meio em que estão. Trazendo essa contribuição de Bourdieu para o campo da educação, Nogueira e Nogueira (2002, p. 21) comentam que: "Essa bagagem inclui, por um lado, certos componentes objetivos, externos ao indivíduo, e que podem ser postos a serviço do sucesso escolar". Ou seja, são elementos dimensionados para além do indivíduo e que podem contribuir para o sucesso escolar.

Inserindo-se nessa perspectiva de reconhecimento e valorização da participação do indivíduo em espaços de educação não formal, das implicações desse movimento no seu desenvolvimento, com repercussões na sua trajetória escolar, este estudo direciona-se para uma escuta dos egressos do Programa Curumim do Sesc.

\section{Programa Curumim: um espaço de educação}

O Programa Curumim é um programa de educação não formal que visa à formação integral de crianças de 7 a 12 anos, atendendo prioritariamente crianças de famílias de comerciários e de baixa renda, provenientes, em sua maioria, da região circunvizinha à unidade do Sesc. Ele surge na década de 80, em um movimento do Sesc São Paulo e de muitas outras instituições sociais, como resposta a um contexto de profunda crise social, perscrutando alternativas de transformação, principalmente junto a crianças e adolescentes. Concretamente, são oferecidas para esse público, no contraturno do período escolar, atividades permanentes, de terça a sexta-feira.

O lançamento oficial do Programa Curumim ocorreu em 2 de agosto de 1987, no atual Sesc Pompeia, e consistiu em um grande evento de inauguração que contou com a participação de cerca de 6 mil crianças (OIENO; FERREIRA, 2015). Em seguida, o Programa foi implantado nas unidades de Carmo, Santos, Campinas, Piracicaba e Bauru. Atualmente, o Programa está em funcionamento em 33 unidades do Sesc. Em Taubaté, o Sesc já atuava desde 1948, e sua unidade atual foi inaugurada em 1988, juntamente com a implantação do Programa Curumim. 
O Programa Curumim foi dimensionado de acordo com o contexto local. Ou seja, cada unidade foi orientada a elaborar seus projetos de forma a pautá-los em "suas próprias características, tais como o perfil do público, as competências das equipes, os equipamentos, as instalações e os recursos disponíveis" (OIENO; FERREIRA, 2015, p. 25), o que favoreceu a autonomia, já existente nas unidades, e possibilitou que o Programa Curumim acompanhasse as mudanças dos contextos em que seu público estava inserido.

Desde o início de suas atividades, em 1987, o Programa Curumim busca contribuir para a educação e o desenvolvimento integral das crianças participantes. Para isso, oferece acesso a um conjunto de vivências diversificadas de manifestações culturais, a fim de garantir às crianças o exercício da cidadania. (OIENO; FERREIRA, 2015, p. 29-30).

Dessa maneira, possibilita-se a construção de relações que contribuem nos modos como os indivíduos interagem e são no mundo, relações essas que se tornam possíveis à medida que a instituição oportuniza o acesso a bens e serviços, a valorização da diversidade, o convívio e a interação.

O acesso a bens e serviços verifica-se, por exemplo, nas consultas odontológicas, na distribuição de lanches pensados e preparados por uma equipe especializada, no uso proveitoso do potencial educativo da instituição, seus materiais, equipamentos, espaços. Já a diversidade manifesta-se no convívio e na interação com a equipe de educadores - composta por profissionais de diferentes áreas -, com as demais equipes da unidade, com o público frequentador e os participantes de outros programas (que, em sua composição, variam, principalmente, entre idosos e crianças) e com o próprio grupo de que fazem parte, o qual é constituído por crianças de 7 a 12 anos, muitas delas oriundas de diferentes bairros, escolas, culturas.

As próprias atividades são diversificadas com a intenção de proporcionar vivências e experimentações. Exemplos das atividades são “educação socioambiental, brincadeiras, teatro, dança, literatura, música, esporte, cinema, jogos, artes visuais, internet, culinária, rádio, blogue, TV, jornal, circo, contação de histórias, festas e passeios diversos" (OIENO; FERREIRA, 2015, p. 33). Há também as contratações de serviços, que são feitas para atender a questões pontuais do grupo que não sejam totalmente possíveis de serem desenvolvidas com os profissionais e as estruturas presentes na unidade.

Nesse sentido, é importante considerar que o Programa Curumim é parte de um conjunto de outras ações desenvolvidas para atender às diretrizes estabelecidas pelo Sesc São Paulo em um documento denominado Programa Integrado de Desenvolvimento Infantil (PIDI), elaborado em 1986 e válido para todas as unidades do estado. Esse documento é resultado de um estudo realizado pela instituição sobre o seu público infanto-juvenil. Ao considerar o contexto de crise social da 
época e, em especial, suas implicações para o público infanto-juvenil, a instituição constatou a urgência de um posicionamento que questionasse práticas e reconhecesse as diferenças e as singularidades desse público. Assim, propôs uma forma democrática de atuação em prol do florescimento da autonomia, procurando superar concepções que desqualificassem esses indivíduos (SESC, 1986).

O PIDI considera a criança como cidadã, um ser em formação portador de direitos, que deve ser respeitado por suas singularidades e interpretado em sua realidade existencial concreta. Nessa direção, a finalidade apresentada no documento é a promoção do desenvolvimento integral da criança, fortalecendo o acesso a bens culturais e tecnológicos e contribuindo para a participação na vida em sociedade como cidadãos conscientes, que são afetados pelas mudanças e pela desigualdade social.

Destaca-se, nas diretrizes desse documento, a ludicidade como um valor necessário para a ação pedagógica, um requisito para que a criança mantenha sua identidade e sua própria razão de ser: "a vida como brinquedo, que é seu modo de vivenciar e compreender o mundo" (SESC, 1986, p. 13). Com esse intuito, propõe-se a realização de atividades em grupo que possibilite a diversidade etária, assim como a participação ativa e autônoma, de forma que os "conteúdos" a serem aprendidos não se pautem somente em conceitos.

Entre as diretrizes estabelecidas pelo PIDI que orientam as ações do Programa Curumim, está manifestada a preocupação em:

Proporcionar o uso do tempo livre das crianças por um conjunto de atividades integradas
que possibilitem sua socialização, desenvolvimento psicomotor, sua expressão sensível e
desenvolvimento físico, bem como o domínio do meio em que vive. (SESC, 1986, p. 17).

Em outras palavras, o Programa procurou, a partir do tempo livre, possibilitar às crianças a participação e a elaboração de atividades que proporcionassem sua formação integral, de modo que elas lidassem com situações reais, relacionando-se com o outro e com o meio de forma autônoma e sendo respeitadas por suas características e singularidades.

A estruturação de conteúdos seguindo o PIDI pautava-se em cinco módulos, quais sejam: i) Expressão sensível; ii) Expressão física; iii) Relações com a natureza; iv) Relações com a ciência e a tecnologia; e v) Relações com a sociedade. Não obstante, as unidades tinham autonomia para implementar quantos e quais desejassem desenvolver, tendo como principais objetivos o aproveitamento de todo o potencial das instalações das unidades e o atendimento às famílias, que teriam onde deixar seus filhos. Pretendia-se, desse modo, acolher essas crianças e integrá-las no cotidiano por meio da educação e da recreação. 
Cabe ainda registrar que, além das atividades permanentes oferecidas pelo Programa Curumim, seus participantes poderiam acompanhar diversas outras ações, denominadas eventuais e de apoio. As atividades eventuais e os projetos especiais apresentam flexibilidade em suas realizações e procuram atender a sazonalidades, tais como período de férias, fins de semana, datas festivas. São momentos que não pertencem à rotina diária, mas que podem oportunizar diversão e novos momentos de aprendizagem, materializando-se na forma de viagens, gincanas, festivais, campeonatos, excursões, feiras, shows, teatro, cinema, exposições. Já as atividades de apoio são voltadas para parcerias que possam assistir, principalmente, aqueles que são considerados vulneráveis economicamente. São elas: serviços de prevenção odontológica, exame médico e fornecimento gratuito de lanche diário.

Desse modo, observa-se que, ao fazer parte do Programa Curumim e realizar as atividades, a criança passa a ter acesso a uma acolhida mais ampla e a frequentar um ambiente planejado, no qual ocorre um conjunto de outras atividades culturais, esportivas e de lazer. No anseio de descortinar os sentidos dessa participação no processo formativo e as repercussões na vida escolar, esta pesquisa procurou escutar seus egressos.

\section{A escuta dos egressos: visitando memórias, descobrindo sentidos}

Como pontuado anteriormente, este artigo deriva de uma pesquisa mais ampla que, a partir das falas dos egressos do Programa Curumim, buscou investigar a contribuição desse programa para a formação dos participantes. O contato com os egressos foi efetuado por meio das redes sociais Facebook, Instagram e Whats App, o que possibilitou o envio e o subsequente acesso a um link para um questionário elaborado no aplicativo Google Forms. Além de solicitar o consentimento em participar da pesquisa, foram propostas questões abertas sobre a participação no Programa Curumim e sobre a disponibilidade em participar de uma entrevista semiestruturada. O retorno foi rápido, com 24 questionários respondidos em um prazo de 24 horas. Esse primeiro contato garantiu uma aproximação com o contexto dos egressos, o que permitiu ampliar a análise e subsidiar o próprio roteiro da entrevista. Assegurou, ainda, o público desta, sendo selecionados os quatro primeiros que, ao responderem, dispuseram-se a participar, no caso, quatro mulheres na faixa de 18 a 31 anos, especificamente, duas de 31, uma de 30 e uma de 18 anos. Formalizado o contato, elas foram entrevistadas conforme sua preferência, duas de modo online e duas presencialmente, respeitando os protocolos e determinações sanitárias decorrentes da pandemia do Covid-19. 
A partir das respostas coletadas nos questionários e nas entrevistas, procedeu-se a uma análise estruturada, especificamente, a análise de conteúdos proposta por Bardin (2011, p. 126). Seguindo a abordagem da autora, os dados coletados na entrevista foram transcritos, de forma que se iniciou a "leitura flutuante", a partir da qual foi possível recolher impressões e efetuar uma análise "mais precisa". Desse modo, prosseguiu-se com a escolha e a estruturação das categorias, geradas das questões norteadoras e recortadas dos temas que se repetiam. Esses temas recorrentes contribuíram para uma categorização mais significativa da fala das egressas, coerente com as memórias trazidas à tona, atribuindo-lhes sentido. Agrupar os temas recorrentes originou três blocos de análise e reflexão: (a) memórias e vivências; (b) espaço e criação de vínculo; e (c) construção de si. Ao analisar as categorias, identificou-se que a incursão das egressas na educação não formal contribuiu para o processo de interação e bagagem cultural, repercutindo significativamente no desenvolvimento da educação formal.

Além disso, a pesquisa possibilitou que, mesmo de forma distante, as vozes dos egressos ecoassem. Isso permitiu que a experiência vivenciada no Programa Curumim pudesse ser concretizada a partir das memórias do espaço que viabilizou vínculos significativos entre os participantes, a instituição e o processo de aprendizagem e que, consequentemente, promoveu a construção de si dentro de um espaço coletivo.

\section{Memórias e vivências}

Reconhecendo que o trabalho com memória revela parte da história, compreende-se que o processo de escuta das egressas lida com diferentes perspectivas. Tais perspectivas podem apresentar limitações, uma vez que a "[m]emória é seletiva. Nem tudo fica gravado. Nem tudo fica registrado" (POLLAK, 1992, p. 203). Ademais, a memória sofre interferências e pode ser demarcada por sensações que o participante sentiu ou sente ao relembrá-las.

[...] pois a realidade não pode ser apreendida no seu todo e a ela são dados sentidos segundo pontos de vista. Logo, é sempre, literalmente, parcial. Entretanto, o que se busca é a construção de uma versão o mais próxima possível do universo recortado da realidade, através da inclusão e discussão de diversos olhares e falas dos sujeitos envolvidos. (FERNANDES, 2005, p. 15).

Mesmo compreendendo as limitações e a seletividade das memórias, verificou-se que estas, delineadas pelas egressas, foram fatores de grande significância no processo formativo, pois, na sua totalidade, as entrevistadas apontaram as contribuições sobre a participação no Programa Curumim. Essas vivências guardadas na memória são repletas de aprendizagens marcantes. 
Nesse contexto, as egressas reportam-se às memórias das viagens e passeios, que foram descritas como oportunidades de conhecer outras cidades, assim como de participar de eventos mediados pelos educadores e outros profissionais, como visitas a museus, parques florestais, praias, entre outros. Essas falas denotam a expansão de conhecimentos e a construção de algumas noções, dentre as quais destacamos as seguintes: "[...] eu nem sabia que existia outros Sesc naquela época”; "E cada relação nova que a gente faz é a experiência, né. Vivência. Eu consigo, falando dessas viagens, eu consigo lembrar muito bem e com clareza o que eu vi, o que eu conversei com as pessoas"; "[...] nem sempre a gente tinha noção de onde era".

As diferentes vivências geram o acesso a um conjunto de processos que cooperam para o diálogo entre a realidade na qual estão inseridos e as demais, cultivando a sociabilidade. "É neste sentido que uma pedagogia da autonomia tem de estar centrada em experiências estimuladoras da decisão e da responsabilidade, vale dizer, em experiências respeitosas de liberdade" (FREIRE, 2013, p. 105).

As falas das egressas são carregadas de lembranças prazerosas, como: "Era um período... era gostoso... tipo, rolava aquela ansiedade, tipo, que atividade que vai ter hoje..."; "Tinha carteirinha do clube do Sesc e tinha carteirinha do Curumim. Era mor bonitinha, era uma carteirinha azul ate"; "[...] uma recordação muito boa, né. Esses dias alguém daqui da região postou uma foto daquela teia de aranha, tinha ali na frente, então, tipo, se você não se ralou nisso aqui na sua infância, você não conheceu o Sesc".

Assim, ao trazer à tona as memórias vivenciadas no espaço do Sesc, as egressas entrevistadas pontuam as aprendizagens significativas e a criação de vínculos fundamentais na constituição dos sujeitos.

\section{Espaços e criação de vínculos}

As egressas entrevistadas demonstraram ter uma relação de proximidade com a instituição antes de entrar no Programa Curumim, pois eram frequentadoras do Sesc. Todas elas, em algum momento, moraram próximo à instituição, criando, assim, um vínculo geográfico com o espaço, o que nos leva a presumir que o espaço, além de acessível, tornou-se referência de segurança e lazer, o que pode ter contribuído para o desenvolvimento de um vínculo afetivo. "É bem essa relação com Sesc mesmo, era o quintal da nossa casa".

A relação com o espaço evoluiu de tal forma que se tornou um hábito familiar. Uma das egressas comenta que seu filho é um frequentador assíduo do Sesc atualmente, de modo que é reconhecido pelos funcionários; ela também expressa a dificuldade sofrida em razão do fechamento 
da unidade durante o período de isolamento social: "Ele sofre até hoje, por não conseguir entrar no Sesc [...]. Mas não tá podendo [...]”.

Nos relatos, as entrevistadas revelam que, inicialmente, frequentavam o Sesc em virtude das peças de teatro, da piscina, das atividades de fim de semana e de outros programas direcionados à infância. Mas explicam que, posteriormente, o vínculo estendeu-se para além da infância: "até dias antes de me mudar para Campo Grande, Mato Grosso do Sul, en tava fazendo a minha matrícula do Sesc Taubaté".

O conjunto de atividades que a instituição oferece favoreceu o vínculo dos egressos com o espaço. Isso porque, no mesmo lugar, é possível encontrar peças de teatro, ginástica multifuncional, piscina, curso de culinária, de artesanato, oficinas, shows, atividades para todas as gerações, entre outras opções, além de ser um espaço com áreas verdes, com diferentes profissionais e equipamentos. "Enfim, o Sesc me proporcionou uma coisa muito legal, no sentido assim de eu me preocupar com a minha saúde, física, mental. De higiene bucal, é tudo... Devo ao Sesc". "É uma coisa assim que en falo que en não quero largar nunca".

Para uma das egressas que foi estagiária do esportivo e depois educadora temporária do Programa Curumim, o relacionamento com a instituição foi além do papel de frequentadora, passando para o vínculo profissional. E, para ela, isso "foi tipo a realização de um sonho", "e foi legal que teve troca, né, de conbecimento profissional, troca de conhecimento da vida assim”. Essa valorização do ambiente vai ao encontro das reflexões de Bestetti (2014, p. 605):

\footnotetext{
O aumento da interação social torna-se, também, mais espontâneo e significativo, a partir da possibilidade de encontros em ambientes que permitam escolhas. Entendendo que cada pessoa é diferente da outra, vinda de um cotidiano e espaço social específico, buscase criar ambientes que permitam ao usuário preservar sua identidade.
}

A relação entre os participantes, os educadores e o ambiente demonstra proximidade e carinho. Nota-se, diante das declarações, um sentimento vinculado à amizade, à liberdade, de conhecimento e reconhecimento. "Era muito aberta e a gente brincava muito. A gente tinha liberdade pra falar, pra reclamar, pra pedir e tinha muito respeito, né. [...] Era muito gostoso porque era muito leve a relação, não tinha cobrança. [...] Eu não consigo explicar de tão bom que era. "[...] não é uma criança que ele só tá vendo no Curumim durante o ano e depois, acabou o ano, vem outra turma, né. Eles viram a gente crescer, né".

Observa-se que, tanto na participação no Programa Curumim quanto nas demais atividades, as egressas salientam que o espaço proporcionou vínculos significativos, corroborando a construção de si. 


\section{A construção de si}

O Sesc evidencia sua intencionalidade educativa ao manter os espaços conservados, oferecer diferentes propostas de lazer, expandir o repertório cultural, explorar os conhecimentos regionais, propor inovações, promover experiências que os frequentadores vivenciam na instituição e transformá-las em marcas do que foi vivido e sentido. Fernandes (2005, p. 2) menciona que o "vivido implica em ter passado pela experiência, ter sido exposto ou expor-se, ter permitido o acontecimento em si do conhecido e do novo, do inusitado, do imprevisto. Implica criar significados. A vivência permite o conhecimento". E isso demonstra que não há espaços e tempos corretos para a aprendizagem - todos os tempos e os espaços são propícios à aprendizagem.

As egressas, durante a entrevista, confirmaram essa constatação do autor, ao relatarem contribuições para a construção de si, tais como a superação da timidez, o sentimento de partilha, a convivência para além da família e colegas de escola, a relação com crianças de diferentes idades, contextos e personalidades. "Significou a construção do meu eu, né. De quem eu sou. [...] Eu gosto muito. Eu falo muito pras pessoas até hoje... Quando eu faria Curumim... Sabe? Tá cravado em mim. Esse men jeito de ser, eu devo ao Curumim". "[...] porque o Curumim mostra que as pessoas são diferentes, né. E uma hora vai ter que conviver todo mundo. Então, me ajudou nisso, tenho amigos dessa época do Curumim até hoje”.

Dessa forma, a passagem pelo Programa Curumim mostrou-se significativa para os egressos, uma vez que a participação em espaços de educação não formal possibilita ao sujeito diferentes vivências, aprendizagem de construção de sua personalidade, postura e interação. Nesse sentido, afirmam as egressas: "Logo cedo, aprendi muitas coisas de grande valor, obtive muitos conhecimentos, aprendi de forma lúdica e fiz. muitas amizades, era muito bom e até hoje lembro dos bons momentos lá". "Me ajudou na convivência". "Lá consegui aproveitar minha infância e faz̧er amigos que levo até hoje". "Influenciou significativamente minha personalidade e simpatia". "Me permitiu desenvolver habilidades de trabalhos em grupo e a capacidade de pensar de forma mais criativa, para resolver problemas".

As diferentes experiências proporcionaram aos participantes que se tornassem sujeitos ativos e autônomos: "O que eu mais gostava era da liberdade de sermos nós mesmos e a constante possibilidade de pensarmos fora da caixa”," experiências essas que podemos considerar empoderadoras, por ampliarem a visão de mundo e concederem ao sujeito condições de autoafirmação.

As narrativas das egressas apontam para as experiências positivas, tanto individuais quanto coletivas. "O curumim era a parte mais legal do meu dia. Lá eu tinha oportunidade de brincar, viajar, aprender coisas novas, interagir com outras crianças, entre outras atividades que marcaram minha infância de forma positiva". "Era muito bem elaborado e organizado", "era incrivel, eu adorava, sempre muito divertido", "um lugar muito gostoso, onde faríamos amizades, obtemos conhecimentos, iamos a passeios, era muito bom”. Considerando o 
impacto intenso da participação nesse espaço para o desenvolvimento do sujeito, podemos referenciar Moura (2011, p. 117):

é possível afirmar que todo "conhecimento de si" é uma questão de ordem individual e coletiva: o sujeito individual (em sua percepção e em sua constituição de si) é colocado em jogo. Os valores, os possíveis, a ação, a materialidade (a matéria humanizada) esbarram na existência do Outro.

Quando o sujeito sente-se parte de um grupo efetivamente, ele estabelece relações duradouras e significativas, o que contribui para a construção das características do grupo e dos indivíduos inseridos nele. Os sujeitos, ao entrarem em contato com a educação não formal, estabelecem laços de pertencimento que podem favorecer a sua participação cidadã. "A educação não-formal capacita os indivíduos a se tornarem cidadão do mundo, no mundo. Sua finalidade é abrir janelas de conhecimento sobre o mundo que circunda os indivíduos e suas relações sociais" (GOHN, 2006, p. 29). Ou, nos termos de um egresso: "O curumim me ensinou a ver o mundo de outra forma". Consequentemente, essa participação contribui para o desempenho na educação formal, escolar, ao abranger elementos fundamentais para a atuação em grupo.

\section{Benefícios da participação no Programa Curumim para a escola}

Embora a pesquisa não tenha focado o aspecto da educação formal, ao longo das entrevistas e, posteriormente, na análise destas, pôde-se observar, na fala das egressas, a sensível contribuição que a educação não formal desenvolvida no âmbito do Programa Curumim trouxe para a escola.

O Programa Curumim é pautado em princípios democráticos e, por conseguinte, busca garantir espaços de diálogo, tendo se demonstrado um ambiente seguro para que os participantes se expressassem. As atividades desenvolvidas permitiam que se expusessem com tranquilidade, sem medo; desse modo, além de estimular a fala, contribuía para o exercício da oralidade, de se fazer entender pelo outro.

Um exemplo nessa direção é quando uma egressa recordou-se de uma situação na qual as crianças não queriam que o colega fosse a uma viagem em razão de seu comportamento com os demais. As reclamações foram tão recorrentes que esse assunto foi debatido em uma roda de conversa, de modo que todos tiveram oportunidade de se posicionar diante da situação, com a mediação dos educadores. O processo de escuta sobre como os participantes sentiram-se diante da situação, tendo o educador como mediador, proporcionou a reflexão e a resolução de forma democrática. 
O processo de ensino-aprendizagem no Programa faz-se na prática e na relação com o meio e com o outro; para isso, é preciso lidar com as diferenças de forma consciente. Segundo Gadotti (2005, p. 5): "As crianças precisam participar, desde muito pequenas, da construção de suas vidas, precisam tomar parte das decisões sobre o que lhe diz respeito"; a autora argumenta, ainda, que a democracia não é inerente às crianças, elas tornam-se democráticas exercendo a cidadania. "A partir dali eu entendi que... Cara, não é possivel que não tenha nada que você não gosta de fazer [...]. Pode não ser o que você esperava, pode não ser cem por cento do que você gostava, mas atividade tá ali. E eu acho que é isso também que a gente leva pra vida. Algumas atividades na vida a gente vai ter que fazer mesmo não gostando".

Essas possibilidades de convivência com grupos etários diferentes, de resolução de problemas e de se expor em público contribuem sobremaneira para as atividades propostas no âmbito escolar, na medida em que exigem do sujeito um posicionamento diante de fatos e circunstâncias. Como destaca uma entrevistada: "Alguns jogos que a gente faria de raciocinio lógico, que eu achei que me ajudou bastante... tanto pra questão de jogos mesmo, quanto pra questão de Matemática".

Observa-se que a participação nessas atividades contribui para a ampliação da bagagem cultural, tendo consequências positivas para a vida escolar. Seguindo Bourdieu (2003a, p. 42), a herança cultural "é a responsável pela diferença inicial das crianças diante da experiência escolar e, consequentemente, pelas taxas de êxito", entendendo por herança cultural não apenas um conjunto de conhecimentos a serem valorizados pela escola, mas, mais do que isso, também um "sistema de valores implícitos e profundamente interiorizados", os quais qualificam as atitudes frente ao sistema escolar.

Além disso, constata-se que, ao ser colocado diante de situações diversas, o indivíduo prepara-se para o exercício de escolhas fundamentais, como a graduação a ser cursada. Uma egressa relembra a elaboração de um jornal e de oficinas de teatro, experiências que lhe foram tão significativas que ela associa seu interesse pelos cursos de teatro e jornalismo a elas. Outra menciona o gosto pelos esportes e o carinho pelos educadores como principais motivos da escolha de sua graduação e como inspiração para sua prática educativa.

Apesar de as egressas pontuarem que a relação entre professores e educandos na escola ocorria sempre de forma vertical, o que lhes era estafante e composto, muitas vezes, de meras “obrigações”, a passagem pelo Programa fortaleceu, mesmo assim, a relação com a escola, bem como apontou novos caminhos. Nas palavras da entrevistada: "É porque en gostava muito de ir no Curumim assim. E ai aquilo me dava praz̧er também de ir na escola"; e "então o que me marcou assim foi a opção de escolha da minha graduação, né. Se não fosse o Curumim, eu não ia fazer Educação Física”. 
Por fim, verifica-se, a partir da memória das egressas, que o Programa Curumim trouxe uma contribuição valiosa para a história de vida e a construção da cidadania, principalmente os sensos de justiça, respeito, organização, de se seguir regras e de se ter responsabilidade política, o que são questões fundamentais para a vida escolar. E é nesse sentido que ora se apregoa "a articulação da educação formal com a não-formal para dar vida e viabilizar mudanças significativas na educação e na sociedade como um todo" (GOHN, 2006, p. 37).

\section{Referências}

BARDIN, Laurence. Análise de conteúdo. São Paulo: Edições 70, 2011.

BESTETTI, Maria Luisa Trindade. Ambiência: espaço físico e comportamento. Revista brasileira de geriatria e gerontologia, Rio de Janeiro, v. 17, n. 3, p. 601-610, jul./set. 2014. Disponível em: https://doi.org/10.1590/1809-9823.2014.13083. Acesso em: 12 ago. 2021.

BOURDIEU, Pierre. A escola conservadora: as desigualdades frente à escola e à cultura. In: NOGUEIRA, Maria Alice; CATANI, Afrânio (org.). Escritos de educação. 5. ed. Petrópolis: Vozes, 2003a. p. 39-64.

BOURDIEU, Pierre. O capital social - notas provisórias. In: NOGUEIRA, Maria Alice; CATANI, Afrânio (org.). Escritos de educação. 5. ed. Petrópolis: Vozes, 2003b. p. 65-70.

BRANDÃO, Carlos Rodrigues. O que é educaşão. 17. ed. São Paulo: Brasiliense, 1986.

FERNANDES, Renata Sieiro. As marcas do vivido sentido: memórias de jovens ex-frequentadores de um projeto de educação não-formal. 2005. 281 f. Tese (Doutorado em Educação) - Faculdade de Educação, Universidade Estadual de Campinas, Campinas, 2005. Disponível em: http://www.repositorio.unicamp.br/handle/REPOSIP/252889. Acesso em: 12 ago. 2021.

FREIRE, Paulo. Pedagogia da autonomia: saberes necessários à prática educativa. 45. ed. Rio de Janeiro: Paz e Terra, 2013.

GADOTTI, Moacir. A questão da educação formal/não-formal. In: Droit à l'éducation: solution à tous les problèmes ou problème sans solution?, 2005, Sião (Suiça). Anais [...]. Sião (Suiça): Institut international des droits de l'enfant, 2005. Disponível em: https://aedmoodle.ufpa.br/pluginfile.php/305943/mod_resource/content/1/Educacao_Formal _Nao_Formal_2005.pdf. Acesso em: 12 ago. 2021.

GOHN, Maria da Glória. Educação não-formal, participação da sociedade civil e estruturas colegiadas nas escolas. Ensaio - Avaliação e Políticas Públicas em Educação, Rio de Janeiro, v. 14, n. 50, p. 27-38, jan./mar. 2006. Disponível em: https://doi.org/10.1590/S0104-

40362006000100003. Acesso em: 12 ago. 2021. 
MARANDINO, Martha. Faz sentido ainda propor a separação entre os termos educação formal, não formal e informal? Ciência e Educação, Bauru, v. 23, n. 4, p. 811-816, out./dez. 2017.

Disponível em: https://doi.org/10.1590/1516-731320170030001. Acesso em: 12 ago. 2021.

MOURA, Carlos Eduardo de. Sartre e a consciência no processo da construção de si: o "Eu" como valor e projeto. In: Seminário de pós-graduação em filosofia da UFSCAR, VII., 2011, São Carlos. Anais [...]. São Carlos: Universidade Federal de São Carlos, 2011. Disponível em: http://www.ufscar.br/ semppgfil/wp-content/uploads/2012/05/carloseduardomoura.pdf. Acesso em: 12 ago. 2021.

NOGUEIRA, Cláudio Marques Martins; NOGUEIRA, Maria Alice. A sociologia da educação de Pierre Bourdieu: limites e contribuições. Educação e Sociedade, Campinas, v. 23, n. 78, p. 15-36, abr. 2002. Disponível em: https://doi.org/10.1590/S0101-73302002000200003. Acesso em: 12 ago. 2021.

OIENO, Maria Alice; FERREIRA, Henrique Barcelos. Curumim: reflexões coletivas sobre um mesmo programa. In: PARK, Margareth Brandini; FERNANDES, Renata Sieiro (org.). Programa Curumim: memórias, cotidiano e representações. São Paulo: Edições Sesc São Paulo, 2015.

POLLAK, Michael. Memória e identidade social. Estudos Históricos, Rio de Janeiro, v. 5, n. 10, p. 200-212, 1992. Disponível em:

http://www.pgedf.ufpr.br/memoria\%20e\%20identidadesocial\%20A\%20capraro\%202.pdf. Acesso em: 12 ago. 2021.

SERVIÇO SOCIAL DO COMÉRCIO - SESC. Programa integrado de desenvolvimento infantil/PIDI. São Paulo: Administração Regional no Estado de São Paulo, 1986. Apostila. 